\title{
The Use of Nicotinic Acid to Induce Sustained Low Plasma Nonesterified Fatty Acids in Feed-Restricted Holstein Cows
}

\author{
J. A. A. Pires and R. R. Grummer ${ }^{1}$ \\ Department of Dairy Science, University of Wisconsin, Madison 53706
}

\section{ABSTRACT}

The objectives were to determine the effects of nicotinic acid (NA) on blood metabolites (experiment 1) and whether successive doses of NA could induce sustained reductions of plasma nonesterified fatty acids (NEFA; experiment 2) in feed-restricted, nonlactating Holstein cows. Experiment 1 was a single $4 \times 4$ Latin square with 1 -wk periods. Each period consisted of $2.5 \mathrm{~d}$ of feed restriction to increase plasma NEFA and $4.5 \mathrm{~d}$ of ad libitum feeding. Treatments were abomasal administration of $0,6,30$, or $60 \mathrm{mg}$ of $\mathrm{NA} / \mathrm{kg}$ of body weight (BW), given as a single bolus $48 \mathrm{~h}$ after initiation of feed restriction. Plasma NEFA concentration decreased from $546 \mu \mathrm{Eq} / \mathrm{L}$ to $208 \pm 141 \mu \mathrm{Eq} / \mathrm{L}$ at $1 \mathrm{~h}$ after the infusion of $6 \mathrm{mg}$ of NA/kg of BW, and to less than 100 $\pm 148 \mu \mathrm{Eq} / \mathrm{L}$ at $3 \mathrm{~h}$ after the abomasal infusion of the 2 highest doses of NA. A rebound occurred after the initial decrease of plasma NEFA concentration. The rebound lasted up to $9 \mathrm{~h}$ for the 30-mg dose of NA, and up to $6 \mathrm{~h}$ for the 6 -mg dose. Experiment 2 was a randomized complete block design with 3 treatments and 6 cows. Starting at $48 \mathrm{~h}$ of feed restriction, cows received 9 hourly abomasal infusions of 0,6 , or $10 \mathrm{mg}$ of NA/kg of BW. Plasma NEFA concentrations decreased from $553 \mu \mathrm{Eq} / \mathrm{L} \pm 24$ immediately before the initiation of treatments to $<100 \mu \mathrm{Eq} / \mathrm{L}$ during hourly infusions of 6 or $10 \mathrm{mg}$ of NA/kg. Data suggest that the maximal antilipolytic response was achieved with the lowest dose of NA. A rebound of NEFA started 2 to $3 \mathrm{~h}$ after NA infusions were terminated. In both experiments, the NEFA rebound period coincided with increases in insulin and no change or increased glucose concentrations, suggesting a state of insulin resistance induced by elevated NEFA. This model for reducing plasma NEFA concentration by abomasal infusions of NA can be used to study the metabolic ramifications of elevated vs. reduced NEFA concentrations. The data demonstrate potential benefits and pitfalls of using NA to

Received December 31, 2006.

Accepted April 20, 2007.

${ }^{1}$ Corresponding author: rgrummer@wisc.edu regulate plasma NEFA and prevent lipid-related metabolic disorders.

Key words: nicotinic acid, antilipolytic, nonesterified fatty acids, bovine

\section{INTRODUCTION}

The vitamin niacin is a precursor of the coenzyme nicotinamide adenine dinucleotide (NAD), which participates in a large number of oxidation-reduction reactions. Niacin can be found in 2 common forms: nicotinic acid (NA) and nicotinamide (NAM). Both compounds have similar nutritional properties, and both can be used in the synthesis of NAD, but are metabolized in different ways and have different properties when given at supraphysiologic levels (Carlson, 2005).

Early studies from the 1960s showed that high doses of NA have antilipolytic effects in mammals. Both oral and i.v. administration of NA boluses lead to dramatic and acute reductions of plasma NEFA, followed by a rebound and subsequent return to baseline (Carlson, 2005). Accordingly, large oral boluses of NA (up to 160 g) caused transient decreases in NEFA concentration in dairy cows, followed by a rebound (Waterman and Schultz, 1972; Waterman et al., 1972; Jaster et al., 1983). In contrast, NAM does not have antilipolytic properties in humans (Carlson, 2005), and oral administration of $12 \mathrm{~g}$ of NAM/d to feed-restricted cows failed to reduce NEFA or BHBA concentrations (Jaster and Ward, 1990).

Although niacin is a feed supplement frequently used in transition diets, improvement of lactation performance is not evident. Furthermore, despite NA antilipolytic properties, plasma NEFA concentrations were reduced in only 1 out of 11 studies when niacin was supplemented (6 to $12 \mathrm{~g} / \mathrm{d}$ of free NA or NAM) to periparturient dairy cows (NRC, 2001). Several factors may explain this lack of success. Effects would not be expected in the bovine if NAM were fed because the active form of niacin modulating adipose tissue metabolism is NA. Additionally, niacin is extensively degraded in the rumen (Zinn et al., 1987; Campbell et al., 1994; Santschi et al., 2005) and absorption through the rumen is probably insignificant (Erickson et al., 1991; Camp- 
bell et al., 1994). Finally, supplementation may have been insufficient to induce a significant and sustained decrease in NEFA, especially when taking into consideration the limited flow of supplemental NA to the intestine (Zinn et al., 1987; Campbell et al., 1994).

Interestingly, the use of high doses of NA has produced inconsistent results. Jersey cows supplemented with $48 \mathrm{~g} / \mathrm{d}$ of free NA from $30 \mathrm{~d}$ prepartum until calving had lower levels of plasma NEFA at calving and less DMI decline during the last week of gestation (French, 2004). Yet the same research group could not replicate these results when both Holstein and Jersey cows were supplemented with up to $98 \mathrm{mg}$ of NA/d per $\mathrm{kg}$ of BW, from $30 \mathrm{~d}$ prepartum to $21 \mathrm{~d}$ postpartum (Chamberlain and French, 2006). We suspect that only a small fraction of the NA was absorbed because a free form of NA was top-dressed in both experiments (French, 2004; Chamberlain and French, 2006). Furthermore, the antilipolytic effects could have been transient and the inconsistent results on plasma NEFA may have reflected the time of blood sampling relative to NA feeding.

In experiment 1 , we hypothesized that NA may be used to decrease NEFA concentrations during feed restriction. We also hypothesized that there is an optimal dose of NA that would promote a prolonged nadir of NEFA concentration, while avoiding the subsequent rebound of NEFA concentrations. In experiment 2, we hypothesized that successive abomasal infusions of NA can promote sustained reductions of NEFA concentrations in feed-restricted Holstein cows.

The ultimate goal of this research was to develop reliable methodology for studying the effects of plasma NEFA concentration on metabolic events such as insulin resistance and development of fatty liver. Findings from these experiments could lead to applied research on the use of protected NA to moderate increases in plasma NEFA concentration in periparturient dairy cows.

\section{MATERIALS AND METHODS}

Nonpregnant, nonlactating cows were fed legume/ grass hay ad libitum starting at least $2 \mathrm{wk}$ before the initiation of treatments, and supplemented with minerals and vitamins to meet or exceed NRC recommendations (NRC, 2001). Cows were allowed free access to water and trace mineralized salt block throughout the experiments. Feed was provided twice daily, except during feed restriction.

Mobilization of body reserves was stimulated by withdrawing legume/grass hay for $48 \mathrm{~h}$ before the infusion of treatments. During periods of feed restriction, cows were supplemented daily with vitamins and minerals that were mixed with wheat middlings (total of $1 \mathrm{~kg} /$ d) to meet requirements (NRC, 2001).

Cows were rumen-cannulated to allow abomasal infusion of treatments (Gressley et al., 2006) and to avoid ruminal degradation of NA. Nicotinic acid $(99.7 \%$ purity; Adisseo USA Inc., Alpharetta, GA) was diluted in water with equimolar amounts of sodium bicarbonate to facilitate solubilization. Each treatment took approximately 1 min to infuse.

Blood samples were drawn from coccygeal vein or artery at 0,24 , and $48 \mathrm{~h}$ relative to initiation of feed restriction. The sample taken at $48 \mathrm{~h}$ of feed restriction corresponded to time 0 of NA infusions. The Animal Care and Use Committee for the College of Agriculture and Life Sciences at the University of Wisconsin-Madison approved all animal procedures.

\section{Experiment 1}

The experimental design was a $4 \times 4$ Latin square with 1-wk periods. Each period consisted of $2.5 \mathrm{~d}$ of feed restriction followed by $4.5 \mathrm{~d}$ of ad libitum feeding to allow the return of plasma NEFA concentrations to baseline and avoid carryover effects.

Body weight ( $808 \pm 39 \mathrm{~kg}$; mean $\pm \mathrm{SD}$ ) was recorded each period on the day before initiation of feed restriction at 5 to $6 \mathrm{~h}$ after morning feed was offered. Body condition score was recorded at the end of the experiment ( $4.0 \pm 0.35$; mean \pm SD; NRC, 2001). Treatments were administered $48 \mathrm{~h}$ after initiation of feed restriction and consisted of a single abomasal infusion of $1 \mathrm{~L}$ of water (control), or the same volume containing 6, 30, or $60 \mathrm{mg}$ of NA/kg of BW. Blood samples were collected from both jugular veins alternating, at 20 and $40 \mathrm{~min}$ and $1,2,4,6,8,12 \mathrm{~h}$ relative to initiation of treatments. An additional sampling time point at $3 \mathrm{~h}$ was added after the first period, because the data indicated it was warranted. Blood sampling was terminated and cows returned to ad libitum feeding $12 \mathrm{~h}$ after initiation of treatments.

\section{Experiment 2}

The experimental design was a randomized complete block design with 3 treatments and 6 cows. Body weight $(824 \pm 47 \mathrm{~kg}$; mean $\pm \mathrm{SD})$ and BCS $(4.1 \pm 0.35$; mean $\pm \mathrm{SD}$ ) were recorded the day before initiation of feed restriction, and BCS was used as blocking factor. After $48 \mathrm{~h}$ of feed restriction, cows received 9 hourly abomasal infusions of water ( $1 \mathrm{~L}$ per infusion), or the same volume of a solution providing a dose of 6 or $10 \mathrm{mg}$ of NA/kg of BW (at $0,1,2,3,4,5,6,7$, and $8 \mathrm{~h}$ relative to initiation of infusions). Final treatment doses were $0,4.9 \pm$ 0.4 , and $8.3 \pm 0.4 \mathrm{~g}$ of NA/h (mean $\pm \mathrm{SD}$ ). Each abomasal 
infusion was preceded by the collection of a blood sample. Hourly blood sampling continued for $4 \mathrm{~h}$ after the last infusion of NA (i.e., at $9,10,11$, and $12 \mathrm{~h}$ relative to initiation of infusions).

\section{Blood Plasma and Serum Analysis}

Blood was drawn into evacuated tubes (Becton Dickinson, Franklin Lakes, NJ) for the separation of plasma (6-mL tubes containing $12 \mathrm{mg}$ of potassium oxalate and $15 \mathrm{mg}$ of sodium fluoride as a glycolytic inhibitor) or serum (6-mL tubes containing clot activator). Tubes for collection of plasma were kept on ice until centrifugation at $920 \times g$ at $4^{\circ} \mathrm{C}$ for $20 \mathrm{~min}$. For collection of serum, tubes were allowed to clot at room temperature and centrifuged at $2,050 \times \mathrm{g}$ at $20^{\circ} \mathrm{C}$ for $30 \mathrm{~min}$.

Plasma samples were analyzed for glucose and NEFA, and serum samples were analyzed for insulin as previously described (Pires et al., 2007). Serum samples from experiment 2 were analyzed for urea nitrogen (Fawcett and Scott, 1960). Intra- and interassay coefficients of variation were 3.1 and $4.9 \%$ for glucose, 3.2 and $3.9 \%$ for NEFA, 5.2 and $6.4 \%$ for insulin, and 3.8 and $2.2 \%$ for serum urea nitrogen, respectively.

\section{Statistical Analysis}

Concentrations of metabolites were analyzed using the MIXED procedure of SAS, version 9.1 (SAS Institute Inc., Cary, NC) with repeated measures in time using Kenward-Rogers adjustment for calculation of denominator degrees of freedom. The model for experiment 1 included the fixed effects of treatment, time, and treatment by time interaction, and the random effects of period and cow. First-order autoregressive covariance structure [AR(1)] was used for analysis of plasma metabolites during the 48-h feed restriction. Spatial power covariance structure was used for the analysis of metabolites after administration of treatments to allow for unequal spacing between sampling times. Heterogeneous variance across treatments was used whenever providing the best fit according to the Schwarz's Bayesian criterion. There were no carryover effects for any of the response variables $(P>0.40)$. Body weight variation across periods was analyzed using repeated measures and AR(1) covariance structure, using cow as random effect and period as fixed effect.

The model for experiment 2 included the fixed effects of treatment, time, and treatment by time interaction, and the random effects of cow and block. For the statistical analysis of glucose and insulin concentrations after initiation of treatments, AR(1) covariance structure was used with either pooled or heterogeneous variance across treatments, depending on which model provided the best fit according to the Schwarz's Bayesian criterion. Compound symmetry covariance structure was used for the analysis of serum urea nitrogen, because models with other covariance structures failed to converge. Residual plots from the models used to study plasma NEFA concentrations showed unequal variances after NA infusions were terminated. As a result, the model providing the best fit allowed for unequal variances by treatment (NA treatments or control) and by time (before or after $9 \mathrm{~h}$ relative to initiation of NA infusions).

To comply with the assumptions of normality and variance homogeneity of residuals, logarithmic transformation was used for the statistical analysis of NEFA and insulin concentrations after infusion of treatments in experiment 1 and for insulin concentrations after initiation of treatments in experiment 2. For these variables, LSM and SEM were estimated from untransformed data, and $P$-values reflect statistical analysis of transformed data.

The significance level was defined at $P \leq 0.05$, and trends toward significance were considered at $0.05<P \leq$ 0.10 . The SLICE option was used to compare treatment differences at individual time points when treatment by time interaction was significant. Values reported are LSM and SEM unless otherwise stated.

\section{RESULTS AND DISCUSSION}

\section{Effect of Feed Restriction on Blood Metabolites}

The effects of feed restriction on blood metabolites are described in Table 1. Results are consistent across experiments 1 and 2, showing that this model of feed restriction is repeatable. Nonesterified fatty acid concentration increased to approximately $550 \mu \mathrm{Eq} / \mathrm{L}$ at 48 $\mathrm{h}$ of feed restriction. In experiment 1 , glucose decreased from 0 to $24 \mathrm{~h}$ of feed restriction and increased at 48 h. Glucose concentration followed the same pattern in experiment 2 , but there were no statistical differences by day. In both experiments, insulin concentration decreased in the first $24 \mathrm{~h}$ of feed restriction and was maintained at identical levels at 24 and $48 \mathrm{~h}$. Serum urea nitrogen was $13.8,13.4$, and $11.1 \mathrm{mg} / \mathrm{dL}$ at 0,24 , and $48 \mathrm{~h}$ of feed restriction $(P=0.01)$ in experiment 2 . The decline in urea nitrogen at $48 \mathrm{~h}$ may reflect the gradual emptying of rumen contents.

\section{Experiment 1}

Doses of NA chosen were based on amounts of NA used in epidemiological studies with diabetic humans, in which up to $2.5 \mathrm{~g}$ of NA/d were administered (Meyers and Kashyap, 2004). Assuming $70 \mathrm{~kg}$ of BW for an average person, this would correspond to $25 \mathrm{~g} / \mathrm{d}$ for a 
Table 1. Effects of feed restriction on blood metabolites and insulin

\begin{tabular}{lccccc}
\hline & \multicolumn{3}{c}{ Time of feed restriction, $\mathrm{h}$} & & \\
\cline { 2 - 5 } & 0 & 24 & 48 & SEM & $P$-value \\
\hline Experiment 1 & & & & & \\
NEFA, $\mu \mathrm{Eq} / \mathrm{L}$ & $198^{\mathrm{c}}$ & $477^{\mathrm{b}}$ & $546^{\mathrm{a}}$ & 35 & $<0.001$ \\
Glucose, mg/dL & $63.3^{\mathrm{a}}$ & $61.0^{\mathrm{b}}$ & $62.9^{\mathrm{a}}$ & 1.6 & $<0.01$ \\
Insulin, $\mu \mathrm{IU} / \mathrm{mL}$ & $23.7^{\mathrm{a}}$ & $14.8^{\mathrm{b}}$ & $14.5^{\mathrm{b}}$ & 1.7 & $<0.001$ \\
Experiment 2 & & & & & \\
NEFA, $\mu \mathrm{Eq} / \mathrm{L}$ & $142^{\mathrm{c}}$ & $445^{\mathrm{b}}$ & $553^{\mathrm{a}}$ & 24 & $<0.001$ \\
Glucose, mg/dL & 63.0 & 60.7 & 63.2 & 1.8 & 0.41 \\
Insulin, $\mu \mathrm{IU} / \mathrm{mL}$ & $20.9^{\mathrm{a}}$ & $14.1^{\mathrm{b}}$ & $11.8^{\mathrm{b}}$ & 2.3 & 0.02 \\
Serum urea nitrogen, mg/dL & $13.8^{\mathrm{a}}$ & $13.4^{\mathrm{a}}$ & $11.1^{\mathrm{b}}$ & 2.1 & 0.01 \\
\hline
\end{tabular}

${ }^{\mathrm{a}-\mathrm{c}}$ Means within a row with unlike superscripts differ $(P<0.05)$.

700-kg BW cow, using a simple direct conversion. We do not have sufficient data about the dose of NA that elicits antilipolytic effects and pharmacokinetics of NA in the bovine. Therefore, the high, intermediate, and low doses were targeted at 50, 25, and $5 \mathrm{~g}$ of NA. The target NA doses were divided by the average BW of all cows at the beginning of the experiment and expressed on a BW basis thereafter. Body weight did not differ statistically across periods $(P=0.80)$, averaging 819 , 807,801 , and $806 \mathrm{~kg}(\mathrm{SEM}=19.7 \mathrm{~kg})$ before periods 1 , 2,3 , and 4, respectively. Doses of NA were $0,5 \pm 0.2$, $24 \pm 1$, and $49 \pm 3 \mathrm{~g}$ (mean $\pm \mathrm{SD})$.

Effects of Treatments on NEFA Concentrations. Abomasal infusion of NA induced significant treatment $(P=0.001)$, time $(P<0.001)$, and treatment by time effects $(P<0.001)$ on plasma NEFA. There was a marked decrease in plasma NEFA concentration, followed by a rebound (Figure 1). The pattern of plasma NEFA decrease was similar during the first hour for the 3 NA treatments. Additionally, the 2 highest doses

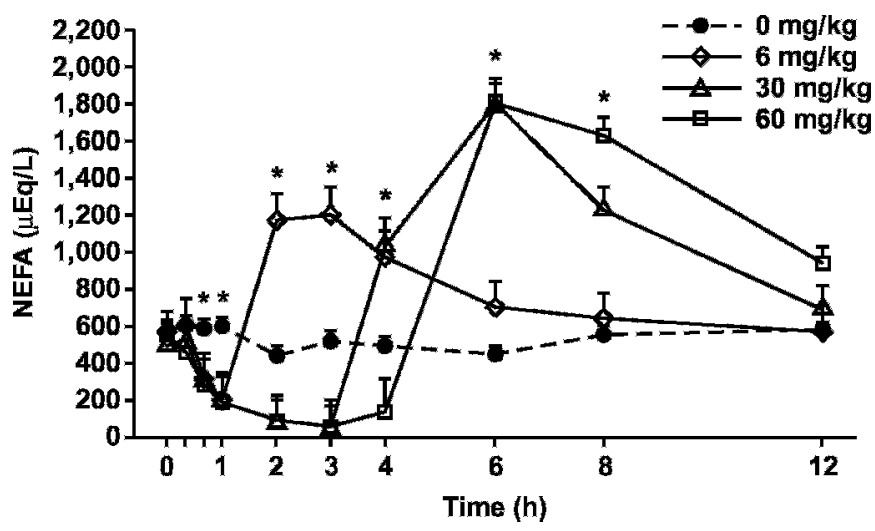

Figure 1. Experiment 1: Effects of abomasal infusion of single doses of nicotinic acid on plasma NEFA. Fixed effects in the statistical model: treatment $(P=0.001)$, time, and treatment $\times$ time interaction $(P<0.001)$. Cows were feed-restricted for $48 \mathrm{~h}$ before administration of treatments. Treatment differences within a time point are indicated by $*(P<0.001)$. of NA (30 and $60 \mathrm{mg} / \mathrm{kg}$ ) caused a similar pattern of NEFA concentrations up to $3 \mathrm{~h}$ after the single infusions. The reduction of NEFA concentration was substantial, from $546 \mu \mathrm{Eq} / \mathrm{L}$ at time 0 (which corresponds to $48 \mathrm{~h}$ of feed restriction) to $208 \mu \mathrm{Eq} / \mathrm{L}$ at $1 \mathrm{~h}$ after the infusion of $6 \mathrm{mg}$ of NA/kg of BW. Three hours after abomasal infusion of the 2 highest doses of NA, NEFA concentrations fell to less than $100 \mu \mathrm{Eq} / \mathrm{L}$. This low level of NEFA was below the concentration before initiation of feed restriction $(198 \mu \mathrm{Eq} / \mathrm{L})$.

Nicotinic acid has antilipolytic effects that occur via stimulation of a G-protein-coupled membrane receptor that is highly expressed in adipocytes, making adipose tissue a preferential target for NA binding (Karpe and Frayn, 2004; Carlson, 2005). Binding of NA to the receptor inhibits adenylyl cyclase, reduces cytoplasmic cyclic AMP concentrations, inactivates protein kinase $\mathrm{A}$, and down-regulates hormone-sensitive lipase activity (Karpe and Frayn, 2004; Carlson, 2005).

Our results show that abomasal infusion of NA at doses used in experiment 1 was sufficient to transiently inhibit lipolysis. The fact that the initial pattern of plasma NEFA decrease was similar across all NA treatments suggests that blood NA concentrations initially reached a threshold that induced maximum inhibition of adipose lipolysis. The rebound of plasma NEFA followed a pattern observed in other animal models. The specific mechanism underlying the rebound phenomenon is not known (Karpe and Frayn, 2004). The magnitude of the rebound depended on either the dose of NA or the duration of time with decreased NEFA, because the 2 highest NA doses caused the longest decrease in NEFA, but also the greatest rebound. The duration of the NEFA rebound did not exceed $9 \mathrm{~h}$ for the $30-\mathrm{mg}$ dose, and lasted 4 to $6 \mathrm{~h}$ for the $6-\mathrm{mg}$ dose. If the magnitude of the rebound was dependent on the dose of NA, and not on the duration of the inhibition of the lipolysis, the use of small boluses of NA might limit the duration and magnitude of the NEFA rebound. 


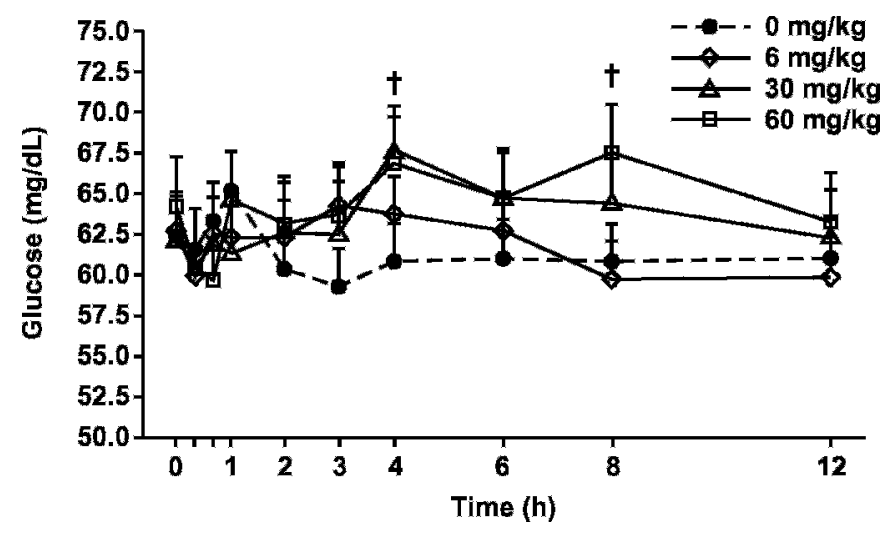

Figure 2. Experiment 1: Effects of abomasal infusion of single doses of nicotinic acid on plasma glucose. Fixed effects in the statistical model: treatment $(P=0.09)$, time $(P=0.06)$, and treatment $\times$ time $(P=0.001)$. Cows were feed-restricted for $48 \mathrm{~h}$ before administration of treatments. Treatment differences within a time point are indicated by $\dagger(P<0.01)$.

\section{Effects of Treatments on Glucose and Insulin} Concentrations. There was a trend for treatment $(P=$ $0.09)$ and time effects $(P=0.06)$ and significant treatment by time interaction $(P<0.001)$ on glucose concentration after the administration of treatments (Figure 2). Glucose concentration increased during the rebound of plasma NEFA (Figure 1). A decrease in glucose concentration was observed during the first 20 min of infusion $(P<0.05)$. This decrease was probably due to a change in the site of sampling from the coccygeal vein at time 0 to the jugular vein thereafter. A 3.2\% decrease in glucose concentration was observed in samples from the jugular vein when compared with samples collected from coccygeal vein in the study of Gelfert and Staufenbiel (1998), but others did not find a difference (Parker and Blowey, 1974). Glucose concentration increased from 20 to $60 \mathrm{~min}(P=0.01)$, which may have been a stress-mediated response because cows were successively tied and sampled from the jugular at 20,40 , and 60 min after initiation of treatments, and adrenaline induces glycogenolysis (Brockman and Laarveld, 1986).We expect glycogen reserves to be present after $48 \mathrm{~h}$ of feed restriction. Liver glycogen was reduced to about $15 \%$ of the fed state $3 \mathrm{~d}$ after feed withdrawal in nonlactating cows (Furll et al., 1993). Others found that liver glycogen was $29 \%$ of the concentration in fed nonlactating cows after $6 \mathrm{~d}$ of feed restriction (Baird et al., 1979).

There was a trend for treatment $(P=0.08)$ and significant time $(P<0.001)$ and treatment by time $(P<$ 0.001 ) effects on serum insulin concentration (Figure 3). Insulin concentrations followed a pattern similar to NEFA concentrations during the rebound phase. The profile of NEFA, insulin, and glucose concentrations

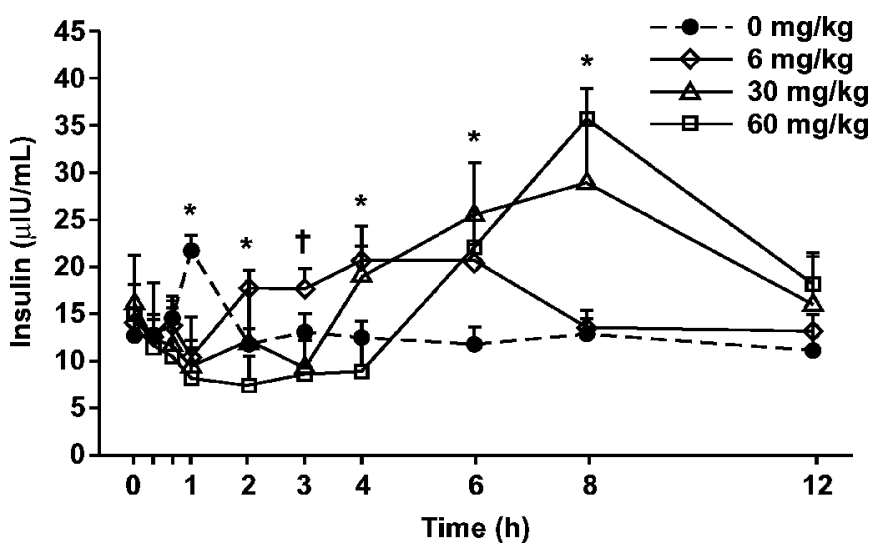

Figure 3. Experiment 1: Effects of abomasal infusion of single doses of nicotinic acid on serum insulin. Fixed effects in the statistical model: treatment $(P=0.08)$, time, and treatment $\times$ time interaction $(P<0.001)$. Cows were feed-restricted for $48 \mathrm{~h}$ before administration of treatments. Treatment differences within a time point are indicated by $*(P<0.001)$ and $\dagger(P<0.01)$.

during the rebound suggested that elevated NEFA concentrations induced an insulin-resistant state. Others found increased glucose and insulin concentration, and impaired glucose tolerance and response to insulin during NA-induced NEFA rebound in goats (Thornton and Schultz, 1980). Elevated plasma NEFA and triglycerides cause insulin resistance in many animal models (Petersen and Shulman, 2006), and we have shown that induction of hyperlipidemia using i.v. infusion of triglyceride emulsion impairs the response to i.v. glucose tolerance test and insulin challenge (Pires et al., 2007).

\section{Experiment 2}

The 2 NA doses tested in experiment 2 (6 and $10 \mathrm{mg}$ of NA/kg of BW per h) were based on the results obtained in experiment 1 . In the first experiment, the infusion of $6 \mathrm{mg}$ of NA/ $\mathrm{kg}$ caused a rebound of NEFA starting $1 \mathrm{~h}$ after treatment was administered. Yet, when cows received $30 \mathrm{mg}$ of NA/kg of BW, NEFA concentration was reduced for $3 \mathrm{~h}$ before the rebound phase started (Figure 1). These results suggested that a bolus of $6 \mathrm{mg}$ of NA/kg could be sufficient to inhibit lipolysis during $1 \mathrm{~h}$, whereas a $30 \mathrm{mg} / \mathrm{kg}$ dose would be effective for $3 \mathrm{~h}$. Therefore, we divided the intermediate dose of NA used in experiment 1 (30 $\mathrm{mg}$ of NA/kg of BW) by a factor of 3 and evaluated hourly infusions of 6 or $10 \mathrm{mg}$ of NA/kg of BW. The use of hourly infusions for both treatments ensured that all cows had the same animal handling and sampling.

Effects of Treatments on NEFA Concentrations. Both NA treatments used in experiment 2 were effective at inducing sustained reductions in plasma NEFA 


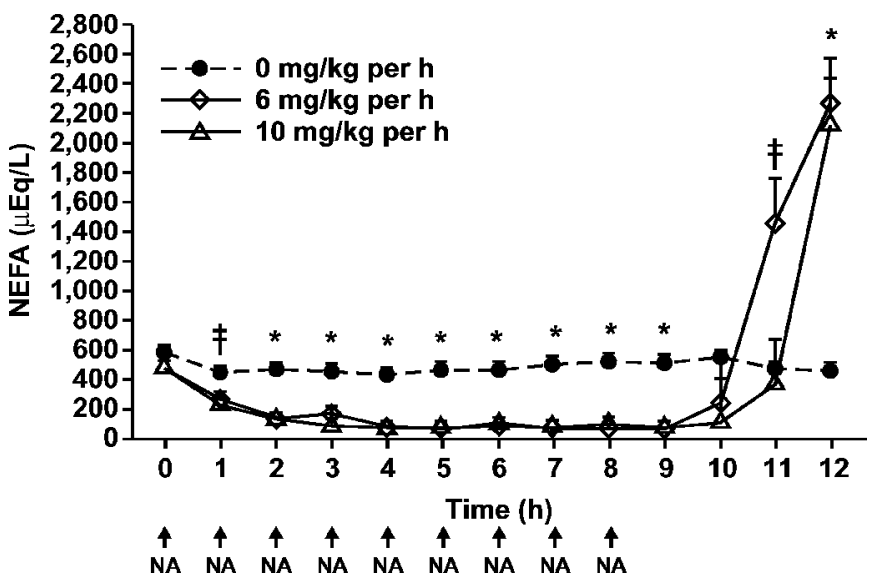

Figure 4. Experiment 2: Effects of abomasal infusions of nicotinic acid (NA) at a rate of 0,6 , or $10 \mathrm{mg} / \mathrm{h}$ per $\mathrm{kg}$ of $\mathrm{BW}$ on plasma NEFA. Infusion of treatments started at $48 \mathrm{~h}$ of feed restriction (time 0 ) and was repeated at $1,2,3,4,5,6,7$, and $8 \mathrm{~h}$ thereafter. Fixed effects in the statistical model: treatment $(P=0.06)$, time $(P<0.001)$, and treatment $\times$ time $(P<0.001)$. Treatment differences within a time point are indicated by $*(P<0.001)$ and $\ddagger(P=0.05)$.

concentrations (Figure 4). There were treatment $(P=$ $0.005)$, time $(P<0.001)$, and treatment by time $(P=$ 0.01 ) effects during administration of treatments (first $8 \mathrm{~h})$. There was a trend for a treatment effect $(P=0.06)$ and a significant time and treatment by time interaction $(P<0.001)$ on samples collected from 0 to $12 \mathrm{~h}$ after initiation of treatments. Nonesterified fatty acid concentrations were decreased to the same extent, from $550 \mu \mathrm{Eq} / \mathrm{L}$ immediately before the initiation of treatments to $<100 \mu \mathrm{Eq} / \mathrm{L}$ during hourly infusions of NA. Data suggest that the maximum antilipolytic response was achieved with the lowest dose of NA, because both doses of NA caused a similar reduction in plasma NEFA throughout the $8 \mathrm{~h}$ of intermittent infusions. Therefore, the shorter duration of reduction of NEFA concentration for cows receiving $6 \mathrm{mg}$ of $\mathrm{NA} / \mathrm{h}$ per $\mathrm{kg}$ of $\mathrm{BW}$ in experiment 1 (Figure 1) was probably due to clearance of the smaller NA dose from blood. Cows used in both experiments 1 and 2 were overconditioned. This was not a deliberate strategy, but rather a result of the having nonlactating cows that were cannulated more than 6 mo before the initiation of the experiment. Future experiments should address whether BCS plays a role in the responses to NA.

A dramatic rebound of plasma NEFA concentration occurred once NA infusions were discontinued (Figure 4). After termination of treatments, a longer time occurred until plasma NEFA rebounded for the high (10 $\mathrm{mg}$ ) dose of NA compared with the low dose $(6 \mathrm{mg})$. This was probably the result of a longer period being needed to clear circulating NA when higher dosages are infused. The period from the last NA infusion to

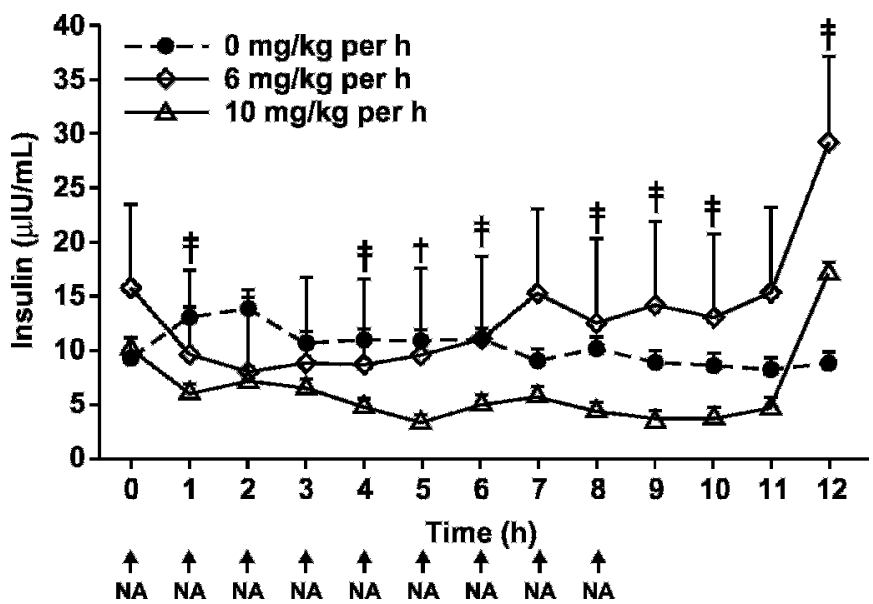

Figure 5. Experiment 2: Effects of abomasal infusions of nicotinic acid (NA) at a rate of 0,6 , or $10 \mathrm{mg} / \mathrm{h}$ per $\mathrm{kg}$ of $\mathrm{BW}$ on serum insulin. Infusion of treatments started at $48 \mathrm{~h}$ of feed restriction (time 0 ) and was repeated at $1,2,3,4,5,6,7$, and $8 \mathrm{~h}$ thereafter. Fixed effects in the statistical model: treatment $(P=0.03)$, time, and treatment $\times$ time $(P<0.01)$. Treatment differences within a time point are indicated by $\dagger(P \leq 0.01)$ and $\ddagger(P \leq 0.05)$.

the initiation of rebound was longer for the 6-mg dose in experiment 2 than in experiment 1 , suggesting the occurrence of some build-up of NA in the blood or adipose tissue due to successive infusions of NA in experiment 2.

Effects of Treatments on Other Blood Metabolites. Interpretation of glucose, insulin, and urea nitrogen concentrations after initiation of infusions requires caution because of limited replication. This study was designed to have sufficient replication for detecting treatment effects on plasma NEFA. Only 2 animals were used per treatment because experiment 1 showed that treatment effects on plasma NEFA were dramatic and highly repeatable and that both cow and period variation was minimal.

There were no treatment $(P=0.60)$, time $(P=0.20)$, or treatment $\times$ time $(P=0.34)$ effects on plasma glucose. Plasma glucose was $63.8,64.5$, and $60.2 \pm 3.0 \mathrm{mg} / \mathrm{dL}$ for cows receiving 0,6 , and $10 \mathrm{mg}$ of $\mathrm{NA} / \mathrm{h}$ per $\mathrm{kg}$ of $\mathrm{BW}$, respectively. The lack of treatment effects suggest that, despite inhibition of lipolysis by NA and drastic reductions in circulating NEFA, feed-restricted nonlactating cows were able to maintain glucose homeostasis. Maintenance of glucose concentration may have been achieved by enhanced reliance on remaining glycogen reserves after $48 \mathrm{~h}$ of feed restriction, from increased mobilization of glucogenic amino acids, or both. There were no treatment effects $(P=0.22)$ nor a treatment by time interaction $(P=0.65)$ on serum urea nitrogen.

There were treatment $(P=0.03)$, time $(P<0.01)$, and treatment by time $(P<0.01)$ effects on serum insulin (Figure 5). Insulin concentrations were increased $4 \mathrm{~h}$ 
after termination of NA infusions, which corresponds to the rebound of NEFA, as observed in experiment 1.

\section{CONCLUSIONS}

This is the first study in which known quantities of NA were infused postruminally. We have shown that NA is a powerful antilipolytic agent in the bovine under negative energy balance due to feed restriction. Furthermore, sustained reductions of NEFA can be achieved as long as the supply of NA for absorption by the lower gut is maintained (Figure 4). This model can be used to study the metabolic and physiologic ramifications of lowering NEFA, without the potential confounding effects that may occur when plasma NEFA concentrations are reduced by changing diet composition, feeding strategies, or glucogenic nutrient supplementation. The infusion of a single high dose of NA caused an acute decline in NEFA concentrations, followed by a rebound during which NEFA increased transiently to $>1,800 \mu \mathrm{Eq} / \mathrm{L}$ (Figure 1 ). Therefore, an alternative approach would be to use the rebound phase to perform studies on the effect of transient increases of NEFA on diverse aspects of metabolism.

In the future, the antilipolytic properties of NA may prove useful in nutritional management of the periparturient dairy cow if ruminally protected and postruminally available sources of NA are developed. Based on the results from our 2 experiments, we postulate that if NA is continuously delivered in sufficient quantities to the intestine, NA will limit lipolysis in adipose tissue, inducing prolonged reductions in plasma NEFA concentration. Furthermore, NA could be used to alleviate catecholamine-stimulated lipolysis at calving, because NA decreases noradrenaline-stimulated lipolysis in nonruminants (Carlson, 2005).

The reduction of plasma NEFA concentration would improve the metabolic profile of the transition cow and prevent energy-related metabolic disorders associated with excessive mobilization of fat reserves (e.g., fatty liver and ketosis). But, before a rumen-protected form of NA can be used, we must first identify a rate of NA delivery that promotes moderate rates of lipolysis and NEFA concentrations, because NEFA originating from adipose tissue is an important energy source and precursor for milk fat synthesis in early lactation (Bell, 1995). For instance, the inhibition of lipolysis in the second week of lactation by hyperinsulinemic-euglycemic clamp reduced plasma NEFA by $68 \%$, but milk fat yield also decreased by $27 \%$ (Corl et al., 2006). Furthermore, a steady supply of NA would probably have to be maintained to avoid the occurrence of a NA-induced NEFA rebound. For example, it needs to be determined if the drop in DMI before calving, and consequent de- crease of NA flow to the lower gut, would exacerbate the peak of plasma NEFA and rate of hepatic triacylglycerol accumulation that occurs at calving (Vazquez-Añon et al., 1994).

\section{ACKNOWLEDGMENTS}

The authors would like to thank UW-Madison Dairy Nutrition students and staff for help during sample collection and processing, S. M. Reynal for assistance with the placement and maintenance of abomasal infusion lines, and the staff at the Dairy Cattle Instruction and Research Center for animal care and feeding. We appreciate the donation of nicotinic acid from Vitaplus Corp. (Madison WI). J. A. A. Pires gratefully acknowledges a fellowship (SFRH/BD/9915/2002) from Fundação para a Ciência e a Tecnologia (Portugal).

\section{REFERENCES}

Baird, G. D., R. J. Heitzman, I. M. Reid, H. W. Symonds, and M. A. Lomax. 1979. Effects of food-deprivation on ketonaemia, ketogenesis and hepatic intermediary metabolism in the non-lactating dairy cow. Biochem. J. 178:35-44.

Bell, A. W. 1995. Regulation of organic nutrient metabolism during transition from late pregnancy to early lactation. J. Anim. Sci. 73:2804-2819.

Brockman, R. P., and B. Laarveld. 1986. Hormonal-regulation of metabolism in ruminants-A review. Livest. Prod. Sci. 14:313334.

Campbell, J. M., M. R. Murphy, R. A. Christensen, and T. R. Overton. 1994. Kinetics of niacin supplements in lactating dairy cows. J. Dairy Sci. 77:566-575.

Carlson, L. A. 2005. Nicotinic acid: The broad-spectrum lipid drug. A 50th anniversary review. J. Intern. Med. 258:94-114.

Chamberlain, J. L., and P. D. French. 2006. The effects of nicotinic acid supplementation during late gestation on lipolysis and feed intake during the transition period. J. Dairy Sci. 89(Suppl. 1):232. (Abstr.)

Corl, B. A., S. T. Butler, W. R. Butler, and D. E. Bauman. 2006. Short communication: Regulation of milk fat yield and fatty acid composition by insulin. J. Dairy Sci. 89:4172-4175.

Erickson, P. S., M. R. Murphy, C. S. McSweeney, and A. M. Trusk. 1991. Niacin absorption from the rumen. J. Dairy Sci. 74:3492-3495.

Fawcett, J. K., and J. E. Scott. 1960. A rapid and precise method for the determination of urea. J. Clin. Pathol. 13:156-159.

French, P. D. 2004. Nicotinic acid supplemented at a therapeutic level minimizes prepartum feed intake depression in dairy cows. J. Dairy Sci. 87(Suppl. 1):345. (Abstr.)

Furll, M., H. Kirbach, and B. Knobloch. 1993. The effects of glucocorticosteroids on lipolysis stimulated by fasting and liver function in cows. Tierarztl. Prax. 21:399-403.

Gelfert, C. C., and R. Staufenbiel. 1998. Proper sampling and handling of blood samples to secure reliable results for the diagnosis of metabolic disturbances in cattle. Prakt. Tierarztl. 79:640-650.

Gressley, T. F., S. M. Reynal, J. J. O. Colmenero, G. A. Broderick, and L. E. Armentano. 2006. Technical note: Development of a tool to insert abomasal infusion lines into dairy cows. J. Dairy Sci. 89:3965-3967.

Jaster, E. H., D. F. Bell, and T. A. McPherron. 1983. Nicotinic acid and serum metabolite concentrations of lactating dairy cows fed supplemental niacin. J. Dairy Sci. 66:1039-1045.

Jaster, E. H., and N. E. Ward. 1990. Supplemental nicotinic acid or nicotinamide for lactating dairy cows. J. Dairy Sci. 73:2880-2887. 
Karpe, F., and P. K. N. Frayn. 2004. The nicotinic acid receptor - A new mechanism for an old drug. Lancet 363:1892-1894.

Meyers, C. D., and M. L. Kashyap. 2004. Management of the metabolic syndrome-nicotinic acid. Endocrinol. Metab. Clin. North Am. 33:557-575.

NRC. 2001. Nutrient Requirements of Dairy Cattle. 7th rev. ed. Natl. Acad. Press, Washington, DC.

Parker, B. J., and R. W. Blowey. 1974. A comparison of blood from the jugular vein and coccygeal artery and vein of cows. Vet. Rec. 95:14-18.

Petersen, F. K., and G. I. Shulman. 2006. New insights into the pathogenesis of insulin resistance in humans using magnetic resonance spectroscopy. Obesity $14: 34 \mathrm{~S}-40$.

Pires, J. A. A., A. H. Souza, and R. R. Grummer. 2007. Induction of hyperlipidemia by intravenous infusion of tallow emulsion causes insulin resistance in Holstein cows. J. Dairy Sci. 90:2735-2744.
Santschi, D. E., R. Berthiaume, J. J. Matte, A. F. Mustafa, and C. L. Girard. 2005. Fate of supplementary B-vitamins in the gastrointestinal tract of dairy cows. J. Dairy Sci. 88:2043-2054.

Thornton, J. H., and L. H. Schultz. 1980. Effects of administration of nicotinic acid on glucose, insulin, and glucose-tolerance in ruminants. J. Dairy Sci. 63:262-268.

Vazquez-Añon, M., S. Bertics, M. Luck, R. R. Grummer, and J. Pinheiro. 1994. Peripartum liver triglyceride and plasma metabolites in dairy cows. J. Dairy Sci. 77:1521-1528.

Waterman, R., and L. H. Schultz. 1972. Nicotinic acid loading of normal cows: Effects on blood metabolites and excretory forms. J. Dairy Sci. 55:1511-1513.

Waterman, R., J. W. Schwalm, and L. H. Schultz. 1972. Nicotinic acid treatment of bovine ketosis. I. Effects on circulatory metabolites and interrelationships. J. Dairy Sci. 55:1447-1453.

Zinn, R. A., F. N. Owens, R. L. Stuart, J. R. Dunbar, and B. B. Norman. 1987. B-vitamin supplementation of diets for feedlot calves. J. Anim. Sci. 65:267-277. 